\title{
An Ethical Ecology of a Corporate Leader: Modeling the Ethical Frame of Corporate Leadership
}

\author{
Robert Joseph Skovira \\ Robert Morris University, Pittsburgh PA USA
}

\author{
skovira@rmu.edu
}

\begin{abstract}
The paper is a discussion of the ethical frame of corporate leadership. The ethical frame is a manager's ethical ecology. An ethical ecology is about the complex weave of moral obligations, intentions, actions, and consequences of doing business. This paper is a discussion of the ethical conceptual model or frame of a corporate leader. The paper looks at the various structural components and relationships of a worldview of ethical management. The structural components are corporate policy and codes of conduct, financial affairs, environmental concerns, human resources, organizational reputation, relationships, and the corporate leader's personal moral frame. The essay discusses these categories of ethical management as organizers of an ethical perspective within a corporate environment.
\end{abstract}

Keywords: corporate ethics, ethical ecology, ethical landscape; corporate leadership, ethical frame; ethical management.

\section{Introduction}

\section{Origin of This Study}

Recent scandals and trials were the initial reason for beginning this essay. Articles appear almost daily in The Wall Street Journal about CEOs and their upcoming trials. Most business sections of newspapers have had several articles, either about the legal times of troubles for big name CEOs or when they overstepped the boundaries of appropriate CEO compensations (or golden parachutes) (Boatright, 2003; Maremont \& Reigber, 2003; Smith, 2003). "One has only to scan the headlines on the financial pages of the world's top newspapers over the past several years to realize why corporate ethics - or the lack thereof - has become perhaps the single most prominent and important business issue of current times and a flash point in the public's eye" (Hemez-

Material published as part of this journal, either on-line or in print, is copyrighted by the Informing Science Institute. Permission to make digital or paper copy of part or all of these works for personal or classroom use is granted without fee provided that the copies are not made or distributed for profit or commercial advantage AND that copies 1) bear this notice in full and 2) give the full citation on the first page. It is permissible to abstract these works so long as credit is given. To copy in all other cases or to republish or to post on a server or to redistribute to lists requires specific permission and payment of a fee. Contact Publisher@InformingScience.org to request redistribution permission.
Broome, Steed \& Lundberg, 2004, p. 3).

Of course, all this talk about graft and corruption began, we can say, with the boondoggle of the Enron scenario, which has certainly underscored the significance of ethical environments. “...Enron's failure was [not] due to faulty accounting or poor regulation, though both of those factors were-and are-very important. Rather, it failed be- 
cause key leaders at Enron lost their moral / ethical direction at the same time that the company was making multibillion-dollar bets on fatally flawed projects" (Bryce, 2002, p. xi).

\section{Some Assumptions}

Leadership is always a difficult mantle to wear. Corporate leadership is a difficult way of being in the world. Its difficulty and challenges are focused on the balancing act among financial concerns, environmental issues, and people. The emphasis in corporate decision making has been on the financial well-being of the firm. This continues. But, now the ethical (moral) dimension has appeared and has been pushed to the foreground, because of the legal situations in which many corporate managers find themselves involved.

Every corporation or organization is a community of practice (Solomon, 1997). Because business is a practiced worldview, business ethics is a way of life, a way of living well within the business world (Solomon, 1992, 1997). The sense of moral action that a corporate leader carries with her in terms of the mental models or interpretative lattices and the cognitive maps that situate her in her business world is a moral consistency supported by a corporation's culture or an organization's climate (Jewels \& Evans, 2005; Sims \& Brinkmann, 2002). Ethics is a theory of moral practice (Sahakian, 1974). Business ethics is a theory about good business practices (Solomon, 1992).

Moral sensibility is about doing what is right (Solomon, 1997). We traverse rather complex cognitive and emotional maps when we concern ourselves with doing what is right. These cognitive and emotional maps (merely a metaphor) are made up of interpretative models that are at the root of our actions. Many of these interpretative lattices are about interacting with people (Solomon, 1992). All of them are learned, hence historical. They are conceptual structures that we have developed (or learned) over the years of experiencing the world and dealing with people in all kinds of situations. These conceptions of doing the right thing structure action, and any considerations of actions (Solomon, 1997).

Being a corporate leader is doing what is right on several different levels or in several different ways. Being a corporate leader is about integrity, responsibility, and excellence, and perhaps even honor (Lennick \& Kiel, 2005). Caesar, it was said, was an honorable man; he had his dignitas. At the end of the day, being a corporate leader means being responsible for more than what is described in the job description. It is about stewardship (McKie, 2003; Nicholson, 1994; Robertson \& Nicholson, 1996; Stodder, 2003).

This essay formulates a view of a corporate leader's ethical ecology. It is a collaborative effort with the informant who is a principal of a company. We begin to tell her story of her ethical framework. It is an insider's picture of the reality of ethical behavior within the worlds of business and corporations. The conceptual construct or model presented here is a result of a collaborative dialogue with the informant. The conception of ethical management is the theory-in-use frame (Argyris \& Schon, 1978) of the ethical landscape. This is the informant's idea communicated through email interviews and phone interviews over 18 month period of time. The CEO keeps a very busy calendar and email and phone interviewing were the most accessible technique (Kolko, 2000).

This conceptual structure (domain) or frame of ethical management (Fielden, 2004; Geertz, 1973; Nicholson, 1994) underlies the actions of this corporate leader in her corporate situation. The theoretical frame is grounded in the situation (Glaser \& Strauss, 1999; Spradley, 1979; Spradley \& McCurdy, 1972; Strauss \& Corbin, 1997). The essay maps the conceptual frame as a theory of right action within a corporate setting by uncovering the fundamental categories of the conceptual structure. 


\section{Frames of Influence}

Our interpretative model (Geertz, 1973) for thinking about the ethical ecology of corporate leadership is to think in terms of frames (Bateson, 1972; Goffman, 1974; Solomon, 1997). Frames of reference are sociocultural constructs that bound interactions within any situation. Frames bracket behavior. Frames are emotional-cognitive models (insider's view) habitually used to understand and deal with situated events; they are the modus operandi for relating to things in our world. They are social models supporting situational action (Geertz, 1973). Frames show up as social models or constructs (outsider's view) used to transact across a situation; they are habitual modes of dealing with recurrent situations and circumstances. They are interpretive habits of everyday experience. They are ways of defining situations (Goffman, 1974; Hall, 1981; Skovira, 2004; Spradley \& McCurdy, 1972). By defining situations, they set up assumptions and constraints. Signs of assumptions are found in the latitude of actions (verbal and behavioral) taken within situations; signs of constraints are the explicit and felt limits in terms of external forces that narrow the range of actions. Definitions of situations are also about expected consequences and results of actions taken. Frames are semantic models; systems of meanings shared. They are how we usually mean things (in what we say and do); frames are habits of sensibility. Frames are interpretative constructs, conceptions, or models, that focus and structure the reality and responsibilities of corporate decision making (Walton, 1988).

Frames are hard to pin down to any one location; they are slippery. They are slippery because they work silently and quietly, in the background (and sometimes they do not appear to work at all). But, frames show up, and make their presence felt, in concrete behavior, in the things we do and say, in what we see and hear (and smell.) They are ambiguous (slippery) because, for the most part, they are constantly being enhanced and elaborated; especially (perhaps only) if the person is reflective about her actions as they articulate intentions and demonstrate consequences and results.

For this occasion (see Figure 1), the frames are national, business, organizational, professional, ethnic, religious, socioeconomic, and familial (Hofstede \& Hofstede, 2005). The national frame is a generalized set of enduring and stable systems of meanings shared by people in a given society. The business world frame is a worldview consisting of typical business practices. The organiza-

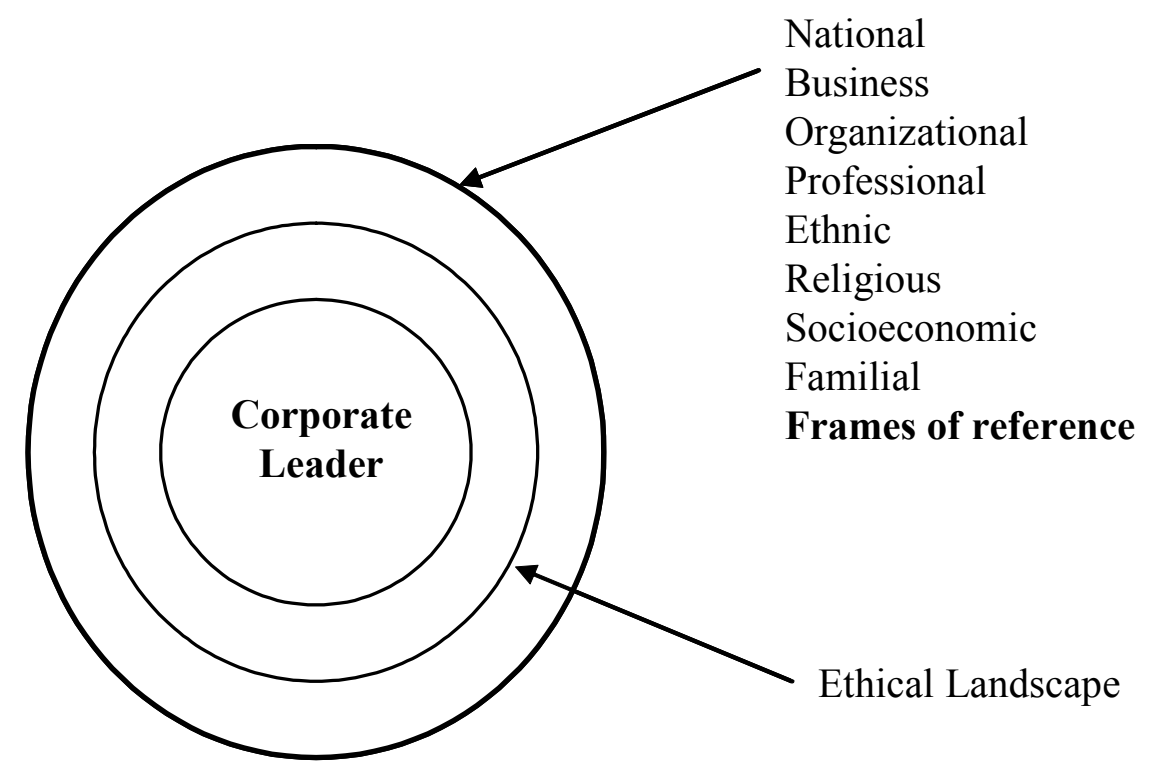

Figure 1: Frames of Influence 
tional frame fits within the business world and elaborates in its worldview the perspective of the business world. The professional frame is the emotional-cognitive and social structure that organizes the everyday work experiences within a corporation. The ethnic frame is perhaps the most ambiguous frame for some; but it is part of one's genealogical background. The religious frame is a structure that channels a view of situations, people, and relationships. The socioeconomic frame organizes social experience. The familial frame is an interpretive view based on the relationships of family (and closely joined, in many cases, with the ethnic and religious frames.) A personal frame (not shown in Figure 1) exists as representative of a person's life-long organizing of those unique socializations and enculturations which work to create distinctive and characteristic styles of action within everyday situations. These are dominant frames of reference. These are the weight-bearing structures of a system. The ecology or system notion simply means that identified (named) components are members of a lattice that has bearing upon a corporate leader's actions. How this lattice is put together and used is a matter of personal justification. The web of frames determines actions and presents justifications.

\section{Notion of Ethical Ecology}

An ethical ecology or landscape (see Figure 2) is the moral landscape within which a corporate leader is situated and makes decisions. An ecological approach to ethical reasoning means that ethical judgments are made within ongoing situations framed by the organizational and business perspectives. Any ethical frame interacts dynamically with other points-of-view; affordances and constraints of other frames of reference shape an ethically charged situation. The ethical landscape is the corporate leader's ethical environment within business and organizational environments, or worldviews; it is one of several primary frames of corporate action (Skovira, 2004). Within the business and organizational worlds, there are assumptions and constraints about the practice of business. Some of the assumptions are estimates of budgets, sales, and possible projects (or work orders). There are actual projects. These become constraints. There are business rules that are also constraints.

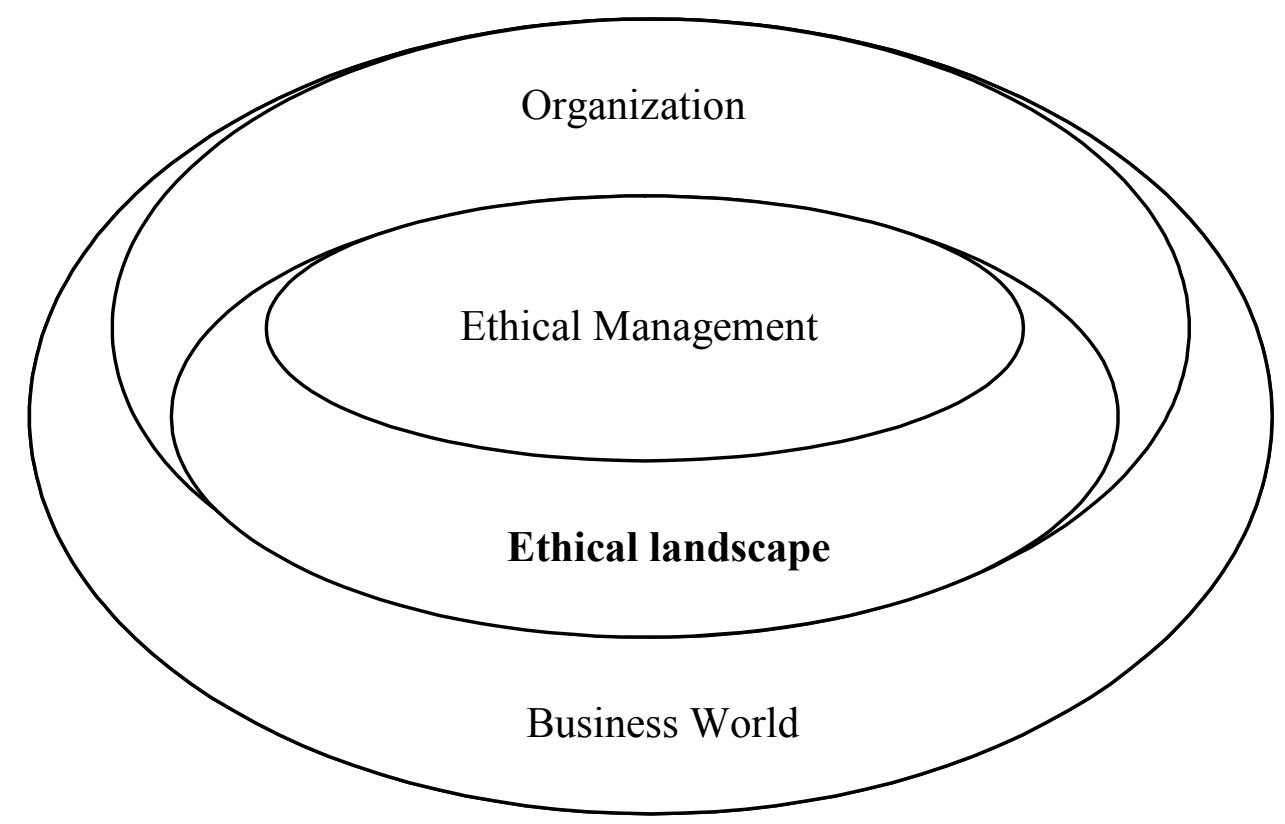

Figure 2: The Ethical Landscape or Frame 
The ethical landscape is both local and global. When viewed from the insider's point-of-view, the ethical landscape is local and personal. The landscape is a horizon of transactions among people, tasks, policies, relationships, and consequences. Everyday experiencing of this mix is complex to say the least and an ethical frame of management becomes a useful way of dealing with moral demands and obligations. The ethical landscape is global in the sense that it stretches out to the organizational point-of-view and the world frame of business (and, perhaps, beyond to national or international concerns.) These are moral horizons that bound with affordances and constraints the corporate leader's actions and decisions which are always local and personal. There are other worldviews or fames. They are the national, ethnic, religious, socioeconomic, professional, and familial (see Figure 1). The religious frame shows up as a category of the model of ethical management (see Figure 3). Thinking about anything as an ecology is thinking about the state of affairs as a system. Actions and consequences are not isolates but interrelated and interactive (Babbie, 2001; Davenport, 1997; Walton, 1988).

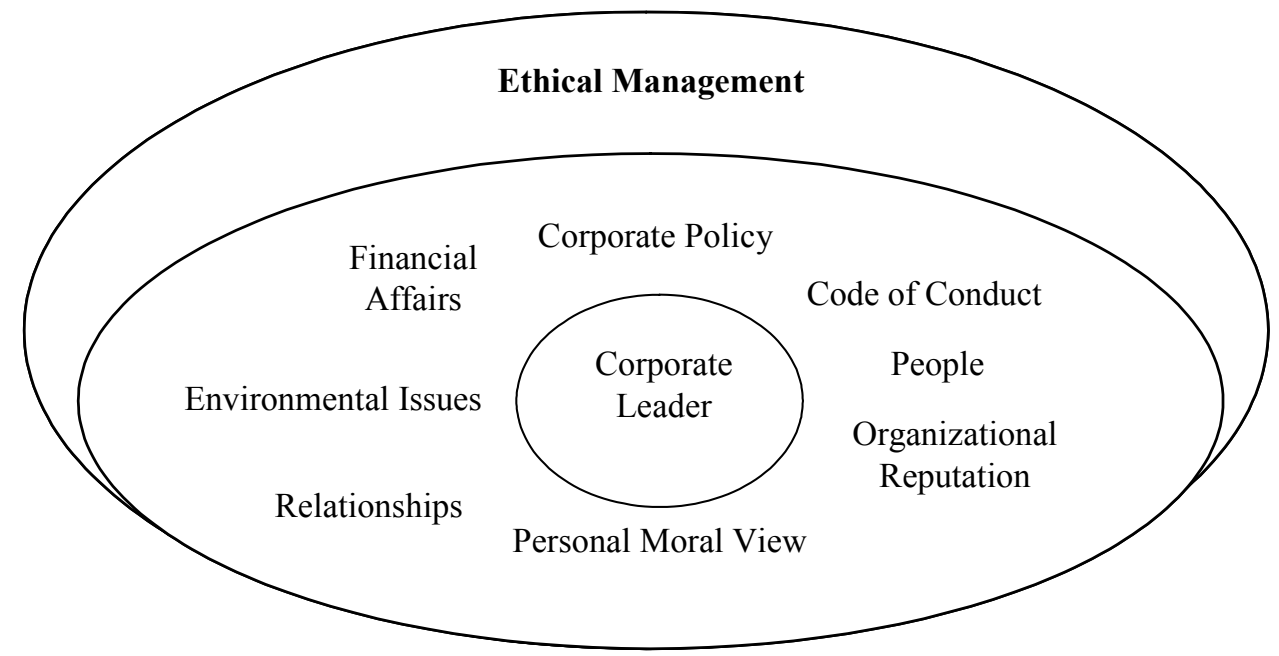

Figure 3: Ethical Management Frame

To think about someone's ethical ecology is to think about the balancing act that is carried on in everyday business dealings, and personal life. This metaphor helps us see the ethical management frame and its components as a rather complex state-of-affairs, an ethical system, where there is a web of transactional relationships. One's ethical landscape is one's ethical frame.

\section{Ethical Management as Conceptual Frame}

The overarching frame of this corporate leader's ethical ecology is the conception of ethical management (see Figure 3). Ethical management is a shared sensibility and conception of ethical actions, an ethic of responsibility (Walton, 1988). There is a common set of underlying rules and beliefs or values that support these rules. A corporate leader's frame or set of defining assumptions about the world affect her moral judgment. It is a knowledge base for corporate moral action (Spradley, 1972). The set of defining assumptions consist of a basic set of beliefs and values. A frame, as a definition of situations encountered and participated in, tacitly expresses a worldview. This worldview is a conception of ethical expectations of a state of affairs (a situation encountered) (Caldwell, Bischoff, \& Ranjan, 2002). These model the ethical perspective that frames behavior. Usually, the rules and supporting beliefs are fully visible to all concerned. Ethical management is the expectation of ethical interaction and relationships with other businesses. In the global economy and dealing with businesses and people of other cultural values, it is important to be explicit about the sense of ethical management (Barth, 2003; Lennick \& Kiel, 2005). 
Ethical management is the conceptual frame or model of the ethical landscape. The model frames relationships and interactions with customers, employees, the market, financials, the environment, suppliers, the corporation, the community and other constituents (Nicholson, 1994). This frame uses corporate policy as a set of criteria for ethical behavior. A corporate leader acts in accordance with these ethical criteria, thus acting within the frame of ethical management (Walton, 1988). The corporate leader is concerned about these things and acting in a way that is consistent the corporate policy on these matters. Corporate policy is a dominant component or subframe of ethical management within the ethical landscape.

Within the ethical management frame, there is a fundamental concern for doing the right thing, as this consequence is envisioned and guided by the operating principles and beliefs of managers. Ethical management is being responsible and maintaining professional and personal integrity. Integrity is maintained by the corporate rules of practice and values in the face of situational demands and temptations created by events and people within the business environment, the corporation, or even personal life. As our corporate informant says:

Ethical management is a set of operating principles and values that are understood and agreed to by members of a society which could be a country, entity such as a company or a group of people agreed to interact. In summary, to me means the full, honest and forthright disclosure and or handling of the situation or matter in accordance with established operating behaviors. The matter is not masked by notes or caveats, statements of halftruths or delayed until more suitable times of disclosure or action. For example, one may become aware of a liability that has been created or obtained in some manner - stating the matter plainly (easily understood) so those evaluating the company for various purposes can see it and understand the magnitude of it.

\section{Architecture of the Conceptual Frame}

The conceptual frame that is ethical management, consists of the categories or subframes that are parts of the corporate leader's ethical landscape (see Figure 2). The architecture of ethical management frame consists of the categories of corporate policy, code of conduct, financial affairs, environmental issues, people, organizational reputation, relationships, and a personal worldview.

\section{Corporate Policy}

The most significant component of the ethical landscape framed by ethical management is corporate policy. These are the corporate guidelines, that are written, and communicated, and enforced, that deal with various situations that are encountered in corporate life. They provide predefined ways of dealing with various states-of-affairs. Corporate policy is important to have and communicate to all employees. Policies are a means to create a way to enforce right action (Barth, 2003; Lennick \& Kiel, 2005). Policies couple ethical actions to ethical guidelines. As our corporate informant says:

Corporate guidelines that are written, communicated and reinforced - meaning the various issues that are encountered and predefined ways of dealing with these issues is important to have and communicate to all employees.

Policies name and define situations and actions. They are also definitions of results and consequences. They identify topical areas and their meanings. As the meanings of topics are defined, so are the actions that embody the company's philosophy. As our corporate informant says:

Yes, corporate policies define norms and expectations for the work environment. We have policies on personnel practices, environmental practices, financial practices, quality and reliability performance policies, industrial safety and health and record integrity and 
dealing with foreign entities and receipt of gifts of considerations that may influence purchasing. There are likely to be many more policies and practices that model and or define ethical concerns and issues. It is important from the framework of the management and employee relationship to be able to be clear about expectations and the way these expectations are clearly communicated is to establish policies and practices.

In the corporate setting, policies are dynamically and interactively generated. They are historical and evolutionary being constructed out of the give-and-take of corporate reality. Policy development happens whenever new situations are encountered across the organization; it also happens as new situations arise relative to other organizations, either as partners or competitors.

\section{Code of Conduct}

Corporate policies state what is right and good corporate conduct. The code of conduct presents what is good employee behavior. Every employee should receive a copy of the code of conduct. The code of conduct is a part of general corporate policy. There is an ethics policy that outlines and specifies ethical behaviors. These rules govern managerial and employee actions. An important element of a corporate code of conduct is the rules being applied to the doing of business.

The beginning point of corporate ethical behavior is a code of conduct that envisions what right corporate behavior is like with the attendant goal that right action fulfills the intentions of the code of conduct (Barth 2003). The intentions and consequential behavior are rules of ethical behavior to be enforced. The guidelines of the code of conduct are meaningless otherwise. As our corporate informant says:

How corporate ethical policy fosters ethical management is in the implementation. Once management is given directives on what behaviors are acceptable, implementation of actions in accordance with these policies reinforces the use and importance of policies. If management is allowed to deviate from these policies without punishment then the policy - even well written policy will not support.

Ethical behavior proves the definitions. It is not enough to define what is to be considered ethical behavior. People must actually act ethically. For people to act ethically in organizations, the ethical frame as envisioned in the code of conduct must be an integral part of the corporation's culture or way of doing things. Ethics is an important part of doing business, both internally and externally. The code of conduct as a significant part of corporate policy is a way of transmuting corporate culture. Corporate cultural behavior is ethical behavior. The culture of the organization supports the ethical actions because the organization's culture values right actions (Barth, 2003; Green, 1994; Walton, 1988)

\section{Financial Affairs}

Financial affairs is another category of the conceptual frame of ethical management (Barth, 2003). It is an important classification of corporate experience within the ethical landscape. This aspect is, in light of the recent scandals, the nexus of legal and ethical concerns. This category represents the appropriate accounting procedures and treatment of financial activities reflecting a business' financial state of health. As our corporate informant says:

In my professional career, I have always been governed by written financial policies that stated how to represent the financials of a company and how to implement responsibilities and represent actions in specific financial terms and approaches. For example, some countries will allow companies in their country to make payments to individuals in the 
government or other sectors in support of winning contracts or securing business. Explicitly the US does not allow such actions domestically or abroad.

\section{Environmental Issues}

Another category of the corporate leader's ethical landscape is environmental concerns. People who design and make products are focused also on the environmental impacts of their products (Barth, 2003). They are aware of short-term and long-term problems stemming from the design and manufacturing processes. Environmental concerns show up in the careful checking for hazardous materials and procedures. There are corporate policies in place to mandate workplace monitoring of people's safety. There are also policies to deal with remediation of historical hazardous situations. As our corporate informant says:

Being good stewards of the environment is a concern for product manufacturers and designers. Dilemmas come into such issues as monitoring the hazards of people in the environment in which they work (health and safety) and beyond that the byproducts of processes employed in the production of products and the resulting environment where a particular product or service is applied.

\section{People}

People are an essential aspect of the ethical landscape. People are an important corporate resource. The ethical management frame dictates that employees be respected and dealt with in a fair manner. Respect for others is an important aspect of this frame (Barth, 2003; Lennick \& Kiel, 2005). It is good for morale because there is a supportive theory about the value placed on what people know and do within the organization. The corporate culture is one of openness. The flow of information is federated (Davenport, 1997) where individuals have the information needed to make their decisions, or to engage in dialogue within the corporate setting. The culture creates an open environment for sharing knowledge across departmental and job boundaries. As our corporate informant says:

The human resource - treating people fairly, respectfully, forthrightly are important elements to corporate ethics. Assuming the environment is safe or hazards are disclosed it is imperative of companies to tell people the facts honestly and forthrightly to enable them to make individual decisions on their course of actions. The environment where people were afraid to raise issues, concerns or disagreements for fear of reprisal created many of the famous "whistleblowers" we read about in the papers and movies are made about (such an Erin Brokovich). In the US, long are the days of slave and child labor largely because the ethics of such decisions do not support these issues in the US society. This is not the policy in other cultures and other parts of the world. Gone are the days when people are viewed as machines and division of labor such that routine tasks were the norm. Neutron Jack (Welsch) the organizational delayer and people remover but building preserver did drive shareholder value and growth. But others were not so fortune in their reckless treatment of people such as "Chainsaw" Al Dunlap who slashed organizations removing people in Sunbeam and others (note check company) and became the failed executive rather than the the[sic] master of organizational dismantling.

This category of the ethical management frame is also about people's support for the mission and vision of the organization. There is support for the corporation's leadership because of the openness of the information flows. They are viewed as partners in the corporate setting, and are loyal to the organization. This loyalty shows up as an concerted effort to produce quality products. 


\section{Organizational Reputation}

Another category of ethical management is a company's reputation. The organization's reputation is how others in other corporations, and surrounding communities, see the actions of the corporation (Barth, 2003; Lennick \& Kiel, 2005). This perception has a moral edge to it because the organization's behavior is always being compared to the story purveyed by brand and marketing experts. Corporate reputation means living up to the expectations fostered by advertising. As our corporate informant says:

...it is the summation of the actions of a corporation. How does the company behave over the long-term. Brand managers, marketing experts who position a product and a company in the minds of the consumer, work hard to create the most favorable position for a company versus competitors in the fulfillment of a consumer's expectation. This is similar to a company's reputation. It is often stated how a company will be and it is the summation of all the experiences various people and entities have with that company. GE brings good things to life - at least that is what their marketing people have said - consumers buy lots of GE things that contribute to a better life in many ways - that reinforces the reputation and GE as a company has operated in a way that they bring good things to life and they do it such that GE is viewed as a good company - a reputation for good.

\section{Relationships}

Another element of the corporate leader's ethical management frame is relationships. The world of business is about forging partnerships and building a sense of community of practices with not only employees, but also with customers and others. Trust-building and loyalty even among fellow corporations is a tenuous affair, especially with the dynamic market (Barth, 2003; Lennick \& Kiel, 2005). Bridges are built with employees as well as customers through communicating the corporation's mission and vision. Crucial aspects here for the ethical management frame are consistency and loyalty to its employees and customers. Another significant aspect is that the corporation must also be flexible in its response to the dynamic market conditions. As our corporate informant says:

Today business is about teaming and relationships with customers, suppliers and other constituents. Short-term results driven companies and markets and building trusting, lasting relationships can be tested when the market moves quickly and the alliances made no longer support the needs of the company. Do you throw out these relationships, do you withhold information from these relationships or spin the information such that it is untrue? Saying what you will do and do what you say is the best policy although it can be most difficult at times.

\section{Personal Worldview}

A final component of this ethical management conceptual frame is the corporate leader's personal frame or worldview. The personal ethical subframe is founded on a biblical moral perspective and a theistic basis of moral action. These provide the moral grounds for justification of the corporate leader's actions and their integration into the ethical landscape, both within the corporate world and outside of it. The informant has elaborated in the passage.

I tend to have a "biblical world view" so morality for me PERSONALLY comes from that perspective. My limited understanding of other world religions often weaves many of the same principles for morality in their religions philosophy. 
This notion is elaborated a bit more in the following passage.

Man's standards for what is right and wrong can change. But God's standards for right and wrong have and will not change. I try to use the Bible to be my ultimate basis for moral/ethical behavior. If it conflicts with the Bible, it conflicts with my ethical standards. That is a pretty altruistic statement, and granted, I have many failures when I compare thoughts and actions against God's word, but it still remains one standard that has not been compromised.

\section{Conclusion}

The model developed and presented here only begins to show the ethical ecology or frame of one corporate leader. An ethical environment consists of actions that display a set of values (concerns and issues about events, actions, and people in the world.). An ethical ecology is an integrated set (the ethical management conceptual frame) of mental models or interpretations on the world. The essay presented the notion of ethical management as a conceptual frame or model of a corporate leader's ethical ecology. The paper has looked briefly at the various structural components of the frame of ethical management. The structural components are corporate policy and codes of conduct, financial affairs, environmental concerns, people, organizational reputation, relationships, and personal moral view. The essay has discussed these categories of ethical management as organizers of an ethical perspective within a corporate environment. The essay presented the conceptual frame of ethical management as a theory of right action within a corporate setting by uncovering the fundamental categories of the conceptual structure.

\section{References}

Argyris, C. \& Schon, D. A. (1978). Organizational learning: A theory of action perspective. Reading, MA: Addison-Wesley.

Babbie, E. (2001). The practice of social research $\left(9^{\text {th }} \mathrm{ed}\right)$. Belmont, CA: Wadsworth / Thomson Learning.

Barth, S. R. (2003). Corporate ethics: The business code of conduct for ethical employees. Boston: Aspatore.

Bateson, G. (1972). Steps to an ecology of mind. Chicago and London: The University of Chicago Press.

Boatright, J. P. (2003). Ethics for a post-Enron America. Phi Kappa Phi Forum, 83(2), 10-15.

Bryce, R. (2002). Pipe dreams: Greed, ego, and the death of Enron. New York: Public Affairs (Perseus Book Group).

Caldwell, C., Bischoff, S. J., \& Karri, R. (2002). The four umpires: A paradigm for ethical leadership. Journal of Business Ethics, 36(1/2), 153-163.

Davenport, T. H. with L. Prusak. (1997). Information ecology: Mastering the information and knowledge environment. New York \& Oxford: Oxford University Press.

Fielden, K. (2004). Exploring the research ethics domain for postgraduate students in computing. Issues in Informing Science and Information technology, 1, 331-340. Available at http://articles.iisit.org/055field.pdf

Geertz, C. (1973). The interpretation of cultures. New York: Basic Books.

Glaser, B. G. \& Strauss, A. L. (1999). The discovery of grounded-theory: Strategies for qualitative research. New York: Aldine De Gruyter.

Goffman, E. (1974). Frame analysis. Boston: Northeastern University Press.

Green, R. M. (1994). The ethical manager: A new method for business ethics. New York: Macmillan College Publishing. 
Hall, E. T. (1981). Beyond culture. New York: Anchor Books Random House.

Hemez-Broome, G., Steed, J., \& Lundberger, S. (2004). The right thing? Leaders speak out on corporate ethics. Leadership in Action, 24(4), 3-6.

Hofstede, G. \& Hofstede, G. (2005). Cultures and organizations: Software of the mind (2 ${ }^{\text {nd }}$ ed.). New York: McGraw-Hill.

Jewels, T. \& Evans, N. (2005). Ethical IT behaviour as a function of environment. Issues in Informing Science and Information Technology 2, 383-393. Available at http://2005papers.iisit.org/I31f24Jewe.pdf

Kolko, B. E. (2000). Intellectual property in synchronous and collaborative virtual space. In R. M. Baird, R. Ramsower, \& S. E. Rosenbaum (Eds.), Cyberethics: Social and moral issues in the computer age (pp. 257-281). Amherst, NY: Prometheus Books.

Lennick, D. \& Kiel, F. (2005). Moral intelligence: Enhancing business performance and leadership success. Upper Saddle River, NJ: Pearson Education Wharton School Publishing.

Maremont, M. \& Reigber, B. D. (2003, October 8). Tyco office blasted; Quattrone hits back. The Wall Street Journal, p. C1.

McKie, S. (2003). The whole truth and nothing but. Intelligent Enterprise, 6(10), 27-29, 36.

Nicholson, N. (1994). Ethics in organizations: A framework for theory and research. Journal of Business Ethics, 13(8), 581-596.

Robertson, D. C. \& Nicholson, N. (1996, October). Expressions of corporate social responsibility in U. K. firms. Journal of Business Ethics, 15(10), 1095-1106.

Sahakian, W. S. (1974). Ethics: An introduction to theories and problems. New York: Barnes \& Noble Books.

Sims, R. R. \& Brinkmann, J. (2002). Leaders as moral role models: The case of John Gutfreund at Solomon Brothers. Journal of Business Ethics, 35(4), 327-339.

Skovira, R. J. (2004). Using informational landscape as a model to understand information use and design within organizations. Issues in Information Systems, 1, 308-314.

Smith, R. (2003, September 25). Two big trials, Quattrone and Tyco, to begin. The Wall Street Journal, p. C1.

Solomon, R. C. (1992). Ethics and excellence: Cooperation and integrity in business. New York \& Oxford: Oxford University Press.

Solomon, R. C. (1997). It's good business: Ethics and free enterprise for the new millennium. Lanham, MD: Rowman and Littlefield.

Spradley, J. P. (Ed.) (1972). Culture and cognition: Rules, maps, and plans. San Francisco: Chandler.

Spradley, J. P. (1979). The ethnographic interview. Fort Worth, TX: Harcourt Brace Jovanovich College Publishers.

Spradley, J. P. \& McCurdy, D. W. (1972). The cultural experience: Ethnography in complex society. Prospect Heights, IL: Waveland Press.

Stodder, D. (2003). Automation alley: Editor's page. Intelligent Enterprise, 6(10), 4.

Strauss, A. \& Corbin, J. (Eds.) (1997). Grounded theory in practice. Thousand Oaks, CS: Sage.

Walton, C. C. (1988). The moral manager. New York: Ballinger Harper \& Row. 


\section{Biography}

Robert Joseph Skovira is a Professor of Computer Information Systems in the Department of Computer and Information Systems at Robert Morris University, Moon Twp. PA 15108. He teaches undergraduate and graduate (MS) courses including Introduction to Java Programming, Advanced Java Programming, Secure Programming, Global, Economic, Social, and Ethical Issues of Computing, Decision Support Systems, Information Design, and Ethical and Legal Issues of Technology. In the Doctor of Science of Information Systems and Communications program, he teaches Ethnography of Information Systems. 